\title{
Desenvolvimento ovariano de Plagioscion squamosissimus (Heckel, 1840) (Actinopterygii, Perciformes), no reservatório de Pedra, Rio de Contas, Bahia
}

\author{
Renata Triane da Silva Félix ${ }^{1,4}$, William Severi ${ }^{1}$, Athiê Jorge Guerra Santos ${ }^{1}$, \\ Ana Carla Asfora El-Deir ${ }^{2}$, Maria Goretti Soares ${ }^{3}$ \& Joaquim Evêncio Neto ${ }^{3}$ \\ ${ }^{1}$ Departamento de Pesca e Aqüicultura, \\ Universidade Federal Rural de Pernambuco - UFRPE \\ ${ }^{2}$ Departamento de Biologia, \\ Universidade Federal Rural de Pernambuco - UFRPE \\ ${ }^{3}$ Departamento de Morfologia e Fisiologia Animal, \\ Universidade Federal Rural de Pernambuco - UFRPE, \\ Rua Dom Manoel de Medeiros, s/n, Dois Irmãos, CEP 52171-900, Recife, PE, Brasil \\ ${ }^{4}$ Autor para correspondência: Renata Triane da Silva Félix, e-mail: renatatfelix@ hotmail.com
}

FÉLIX, R.T.S., SEVERI, W., SANTOS, A.J.G., EL-DEIR, A.C.A., SOARES, M.G. \& EVÊNCIO NETO, J. Ovarian development of Plagioscion squamosissimus (Heckel, 1840) (Actinopterygii, Perciformes), from the Pedra reservoir, Contas river, Bahia. Biota Neotrop. 9(3): http://www.biotaneotropica.org.br/v9n3/en/ abstract?article+bn01909032009.

\begin{abstract}
This study aimed to characterize oocyte organization and maturation stages of Plagioscion squamosissimus ovary. Samples were collected bimonthly in Pedra reservoir, Contas River (BA), between November 2004 and September 2006. Microscopic analyses were made on histological cuts stained with hematoxylin - eosin - phloxine and Gomori trichromic mixture. Five maturation stages were identified through macro and microscopic analysis. Gonad coloration varied according to maturation stages. Six phases of oocyte development were identified: oogonia and perinucleolar, vitellogenic and early lipidic, vitellogenic and intermediate lipidic, vitellogenic and advanced lipidic, and pre-ovulation. Cell structures were similar to those found among marine species, such as oil droplets fusion at later developmental stages and pre-ovulatory hydration. Such features may be explained by the marine origin of Sciaenidae, thus suggesting the need of more detailed studies for understanding the origin, development and function of these structures along oocyte developmental stages.
\end{abstract}

Keywords: vitellogenesis, gonads, histology, pescada, Sciaenidae.

FÉLIX, R.T.S., SEVERI, W., SANTOS, A.J.G., EL-DEIR, A.A.A., SOARES, M.G. \& EVÊNCIO NETO, J. Desenvolvimento ovariano de Plagioscion squamosissimus (Heckel, 1840) (Actinopterygii, Perciformes), no reservatório de Pedra, Rio de Contas, Bahia. Biota Neotrop. 9(3): http://www.biotaneotropica.org.br/v9n3/ pt/abstract?article+bn01909032009.

Resumo: O presente estudo tem por objetivo caracterizar a organização dos ovócitos e os estádios maturacionais do ovário da pescada Plagioscion squamosissimus. As coletas foram realizadas bimestralmente no reservatório de Pedra, rio de Contas (BA), entre novembro de 2004 e setembro de 2006. As análises microscópicas foram realizadas através de cortes histológicos, corados com hematoxilina - eosina - floxina e mistura tricrômica de Gomori. Através da análise macro e microscópica, foram identificados cinco estádios maturacionais. A coloração das gônadas variou de acordo com o desenvolvimento gonadal. Para o desenvolvimento ovocitário, foram definidas seis fases: ovogônia e perinucleolar; vitelogênica e lipídica inicial; vitelogênica e lipídica intermediária; vitelogênica e lipídica avançada e pré-ovulação. Foram observadas estruturas semelhantes às de peixes marinhos, como fusão de gotículas de óleo nas fases finais de maturação e hidratação pré-ovulatória. Estas características podem ser explicadas pela origem marinha da família Sciaenidae, indicando a necessidade de estudos mais detalhados para compreender o aparecimento, desenvolvimento e função dessas estruturas ao longo do desenvolvimento ovocitário.

Palavras-chave: vitelogênese, gônadas, histologia, pescada, Sciaenidae. 


\section{Introdução}

A família Sciaenidae (Owen, 1846) é constituída por espécies predominantemente marinhas e estuarinas, e em número menor de água doce. Atualmente, são conhecidos quatro gêneros estritamente de água doce, para a América do Sul: Plagioscion Gill, Pachyurus La Cepède, Pachypops Gill e Petilipinnis Casatti (Casatti 2003). Plagioscion é representado por cinco espécies válidas (Casatti 2005): P. auratus, P. magdalenae, P. montei, P. squamosissimus e P. ternetzi.

Plagioscion squamosissimus (Heckel, 1840) era originalmente distribuída nas bacias dos rios Orinoco e Amazonas e rios das Guianas, tendo sido mais recentemente introduzida nas bacias do ParanáParaguai-Uruguai e São Francisco, bem como em reservatórios do nordeste do Brasil (Casatti 2005).

No reservatório de Pedra, Bahia, onde a pescada foi introduzida pelo Departamento Nacional de Obras Contra a Seca (DNOCS), há cerca de 30 anos, existem poucos trabalhos sobre sua biologia, podendo-se citar estudos sobre a estrutura da população juvenil (Nascimento 2004) e sobre a alimentação (Trindade 2006).

Apesar de ser uma espécie introduzida, o que usualmente é um problema para a comunidade íctica endêmica (Welcomme 1988), a exemplo do ocorrido em outros reservatórios do Brasil onde a pescada-do-piauí foi introduzida (Agostinho et al. 2007), a mesma apresenta grande valor comercial para o reservatório de Pedra, ocupando o segundo lugar na produção pesqueira local (FADURPE 2006). Aspectos reprodutivos da espécie neste ambiente, contemplando a avaliação do tamanho de primeira maturação, duração e época de desova e fecundidade, requerem conhecimentos adicionais sobre os estádios de desenvolvimento gonadal, fazendo-se necessário um estudo cito e histológico, para identificar as estruturas típicas de cada fase maturacional.

Neste sentido, o presente estudo visa caracterizar o desenvolvimento gonadal de fêmeas da pescada $P$. squamosissimus, com base no desenvolvimento das células germinativas e dos estádios maturacionais do ovário.

\section{Material e Métodos}

As coletas foram realizadas no reservatório de Pedra, rio de Contas (BA), em amostragens bimestrais, entre novembro de 2004 e setembro de 2006. Os exemplares foram capturados através de rede de espera, com malhas de 12, 15, 20, 25, 30, 40, 50 e $60 \mathrm{~mm}$, expostas no período noturno durante 12 horas. Foram analisadas 198 fêmeas, com comprimento padrão entre 64 e $324 \mathrm{~mm}$.
Com base no material coletado, foram mensurados o peso total (PT, g) e o comprimento padrão ( $\mathrm{CP}, \mathrm{mm})$ dos exemplares. As gônadas foram retiradas e pesadas para identificação do sexo e estádio maturacional sendo, posteriormente, realizada análise macroscópica, avaliando aspectos como: coloração, consistência, vascularização, visibilidade dos ovócitos e tamanho em relação à cavidade abdominal, utilizando a escala maturacional de Vazzoler (1996). O Índice Gonadossomático (IGS) foi calculado segundo Vazzoler (1996), sendo IGS = PG/PT*100, onde: $\mathrm{PG}=$ peso da gônada $(\mathrm{g})$ e $\mathrm{PT}=$ peso total (g). Para a caracterização histológica, as gônadas foram fixadas em Bouin e posteriormente transferidas para álcool a 70\%, desidratadas em etanol em ordem crescente de 80 a $100 \%$, diafanizadas em xilol e incluídas em parafina (Beçak \& Paulette 1976, Behmer et al. 1976, Junqueira \& Carneiro 1983). Após a inclusão, o material foi cortado em micrótomo ajustado para $7 \mu \mathrm{m}$. Os cortes obtidos foram corados em hematoxilina - eosina - floxina e mistura tricrômica de Gomori. Após o preparo, as lâminas foram observadas em microscópio ótico e fotografadas em fotomicroscópio Olimpus ${ }^{\circledR}$ BX.

\section{Resultados}

\section{Descrição macroscópica dos ovários}

As observações da morfologia externa da pescada demonstram que esta espécie não possui dimorfismo sexual aparente. Após a incisão abdominal, foi possível a identificação do sexo somente nos indivíduos em estádios de maturação mais avançados, uma vez que os ovários têm estrutura macroscópica semelhante no início da maturação.

Os ovários apresentaram-se como órgãos pares e alongados, localizados na porção dorsal da cavidade abdominal em cada lado da bexiga natatória, ligados entre si através do peritônio, com a extremidade anterior (cefálica) livre, ligando-se na porção posterior final (anal) para formar o oviduto, que se abre para o exterior através do poro urogenital.

Apresentam coloração esbranquiçada e irrigação reduzida na fase imatura. Quando em início de maturação, assumem forma cilíndrica, apresentando uma coloração amarelo-clara, com vascularização mais evidente; e, em final de maturação, os ovócitos são vistos a olho nu, apesar do seu diminuto tamanho.

\section{Caracterização macroscópica dos estádios maturacionais}

As características macroscópicas dos ovários permitiram o reconhecimento de cinco estádios maturacionais: A: Estádio I (Imaturo),
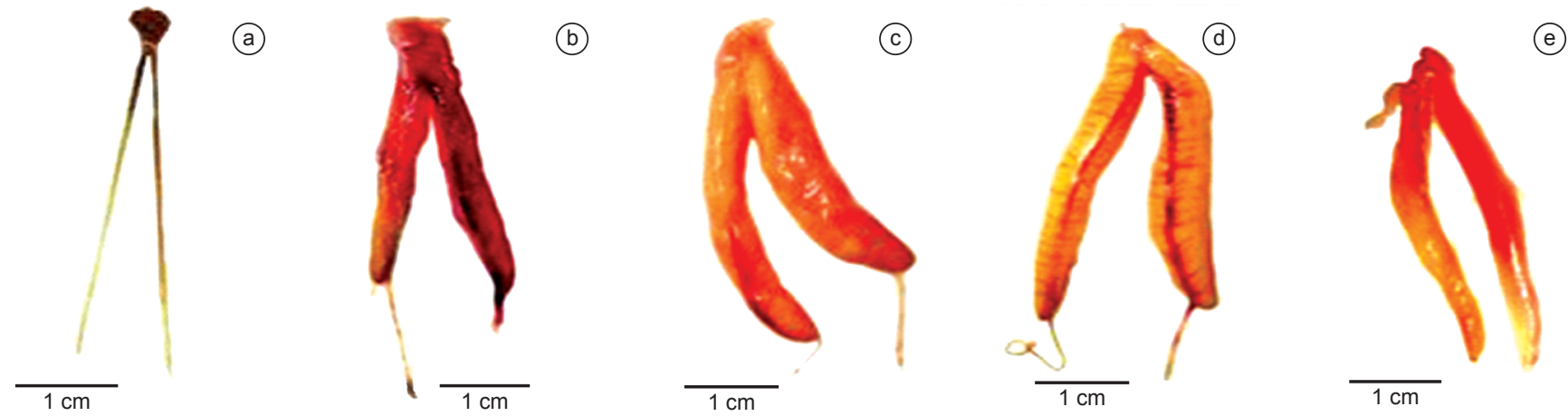

Figura 1. Ovários de Plagioscion squamosissimus coletados no Reservatório de Pedra-BA, em diferentes estádios de desenvolvimento: a) Estádio I (imaturo), b) Estádio IIa (em maturação inicial), c) Estádio IIb (em maturação avançada), d) Estádio III (maduro) e; e) Estádio IV (repouso).

Figure 1. Ovaries of Plagioscion squamosissimus collected in the Pedra reservoir, at different developmental stages: a) Stage 1 (immature), b) stage IIa (initial maturation), c) Stage IIb (advanced maturation), d) Stage III (ripe) and; e) Stage IV (resting). 
B: Estádio IIa (Maturação Inicial), C: Estádio IIb (Maturação Avançada), D: Estádio III (Maduro) e E: Estádio IV (Repouso) (Figura 1).

\subsection{Estádio I (Imaturo)}

Os ovários apresentam estrutura filiforme, são pequenos e sem vascularização. Nessa fase, os ovócitos não são visíveis macroscopicamente. Os exemplares neste estádio apresentaram comprimento padrão entre 64 e $159 \mathrm{~mm}$ e o peso dos ovários variou de 0,003 a 0,22 g (IGS médio: 0,13 \pm 0,08).

\subsection{Estádio IIa (Maturação inicial)}

Apresentam-se mais volumosos, com coloração amarelo-clara e vascularização mediana. Os ovócitos já se tornam visíveis sob estereomiscroscópio. Os exemplares neste estádio apresentaram comprimento padrão entre 140 e $255 \mathrm{~mm}$ e o peso dos ovários variou de 0,05 a 1,01g (IGS médio: 0,28 \pm 0,16).

\subsection{Estádio IIb (Maturação avançada)}

Apresentam as mesmas características do estádio anterior, exceto quanto ao seu tamanho, sendo pouco mais volumosos. Os exemplares neste estádio apresentaram comprimento padrão entre 150 e $324 \mathrm{~mm}$ e o peso dos ovários variou de 0,7 a 4,57 g (IGS médio: 0,69 \pm 0,28).

\subsection{Estádio III (Maduro)}

Os ovários são mais largos, ocupando quase toda a cavidade visceral. Apresentam vascularização intensa e os ovócitos são vistos facilmente a olho nu, apesar de seu diminuto tamanho. Possuem aspecto gelatinoso e coloração amarelo-claro. Os exemplares neste estádio apresentaram comprimento padrão entre 158 e $246 \mathrm{~mm}$ e o peso dos ovários variou de 1,1 a 7,7 g (IGS médio: 1,63 \pm 0,38).

\subsection{Estádio IV (Repouso)}

Apresentam-se ligeiramente alongados, ocupando pouco espaço na cavidade abdominal. Tornam-se transparentes e sem irrigação evidente. A disposição das células permite a visualização de pequenos espaços no interior do ovário, assemelhando-se um pouco ao estádio de maturação inicial. Os exemplares neste estádio apresentaram comprimento padrão entre 154 e $243 \mathrm{~mm}$ e o peso dos ovários variou de 0,01 a 0,5 g (IGS médio: 0,12 $\pm 0,07$ ).

\section{Descrição microscópica dos ovários}

O ovário consiste de lamelas ovulígeras, contendo inúmeros folículos que cobrem os oócitos em seus diferentes estádios. Baseado na morfologia da célula e sua coloração, podem ser identificadas seis fases de desenvolvimento ovocitário.

\subsection{Fase I: Ovogônia e perinucleolar}

As lamelas do ovário contêm folículos cobrindo as ovogônias (16 $\pm 4 \mu \mathrm{m})$, revelando filamentos de cromatinas dentro do núcleo com pouca afinidade ao corante HE. As células maiores são os oócitos na fase perinucleolar $(53 \pm 11 \mu \mathrm{m})$, contendo nucléolo fragmentado na periferia da membrana nuclear. Os oócitos apresentam uma forma irregular, são basófilos e com núcleo grande em relação ao citoplasma (Figura 2a).

\subsection{Fase II: Vitelogênica e lipídica inicial}

Os oócitos são bem maiores que aqueles da fase anterior $(136 \pm 28 \mu \mathrm{m})$. Pequenos grânulos de vitelo começam a aparecer na parte mediana do citoplasma, ao mesmo tempo em que se encontram também pequenas gotículas de óleo na parte mais interna da célula próxima ao núcleo. Parte do citoplasma e do núcleo são acidófilos. A relação núcleo/citoplasma é menor do que na fase I (Figura 2b).

\subsection{Fase III: Vitelogênica e lipídica intermediária}

Nessa fase, observa-se um grande aumento no número e volume dos glóbulos de vitelo e gotículas de óleo. O citoplasma, porém, ainda não está completamente tomado por esses elementos $(197 \pm 11 \mu \mathrm{m})$. O núcleo continua diminuindo de tamanho e apresenta contorno irregular (Figura 2c).

\subsection{Fase IV: Vitelogênica e lipídica avançada}

O citoplasma está repleto de glóbulos de vitelo. As gotículas de óleo aumentam em volume e estão agora espalhadas por toda a célula $(322 \pm 50 \mu \mathrm{m})$. Algumas gotículas começam a fundir-se. O núcleo apresenta contorno irregular e encontra-se no centro do oócito. A análise histológica mostra também um contorno irregular do folículo celular e um espaçamento entre este e a membrana interna da célula, provavelmente indicando, desde já, o processo de hidratação pré-ovulatória. (Figura 2d).

\subsection{Fase V: Migração do núcleo}

Essa fase é semelhante à anterior, considerando o tamanho e características morfológicas do oócito. O núcleo, porém, começa a migrar para a periferia (Figura 2e).

\subsection{Fase VI: Pré-ovulação}

O núcleo não é mais visível, pois tem a sua membrana rompida ao chegar à periferia da célula, fazendo com que o seu material nuclear passe para o citoplasma. Aumenta a fusão, tanto das gotículas de óleo como dos glóbulos de vitelo. Hidratação pré-ovulatória presente (Figuras 2f e 2g).

\section{Descrição microscópica e características dos estádios maturacionais}

Os estádios maturacionais foram identificados através da caracterização e quantificação nas diferentes fases de desenvolvimento oocitário.

Os ovários estão revestidos por uma fina camada de tecido epitelial simples pavimentoso, com uma camada conjuntiva subjacente. Abaixo da conjuntiva existe uma camada de fibras musculares, evidenciada pela coloração do Tricrômico de Gomori (Figura 3a). A camada conjuntiva apresenta-se mais espessa durante o estádio de repouso e torna-se mais fina e vascularizada, conforme a maturação gonadal progride.

O estroma de sustentação no interior do órgão (Figura 3c) comporta lamelas ovulígeras, onde estão localizadas as células germinativas e oócitos em diferentes estádios de maturação (Figura 3b), onde se evidenciou variação tintorial nas células e constituintes celulares.

\subsection{Estádio I (Imaturo)}

Apresenta ninhos de ovogônias (16\% em proporção), em sua maioria aderidas às lamelas ovulígeras, e oócitos I (83\%) (Figura 4a).

\subsection{Estádio IIa (Maturação Inicial)}

Apresenta pequena quantidade de células na fase III (6\%), mas ainda predominam as fases I (12\%) e II (81\%)(Figura 4b).

\subsection{Estádio IIb (Maturação avançada)}

Neste estádio, há células nas fases I (6\%), II (69\%), III (19\%) e algumas células da fase IV (6\%), com o núcleo centralizado (Figura 4c). 

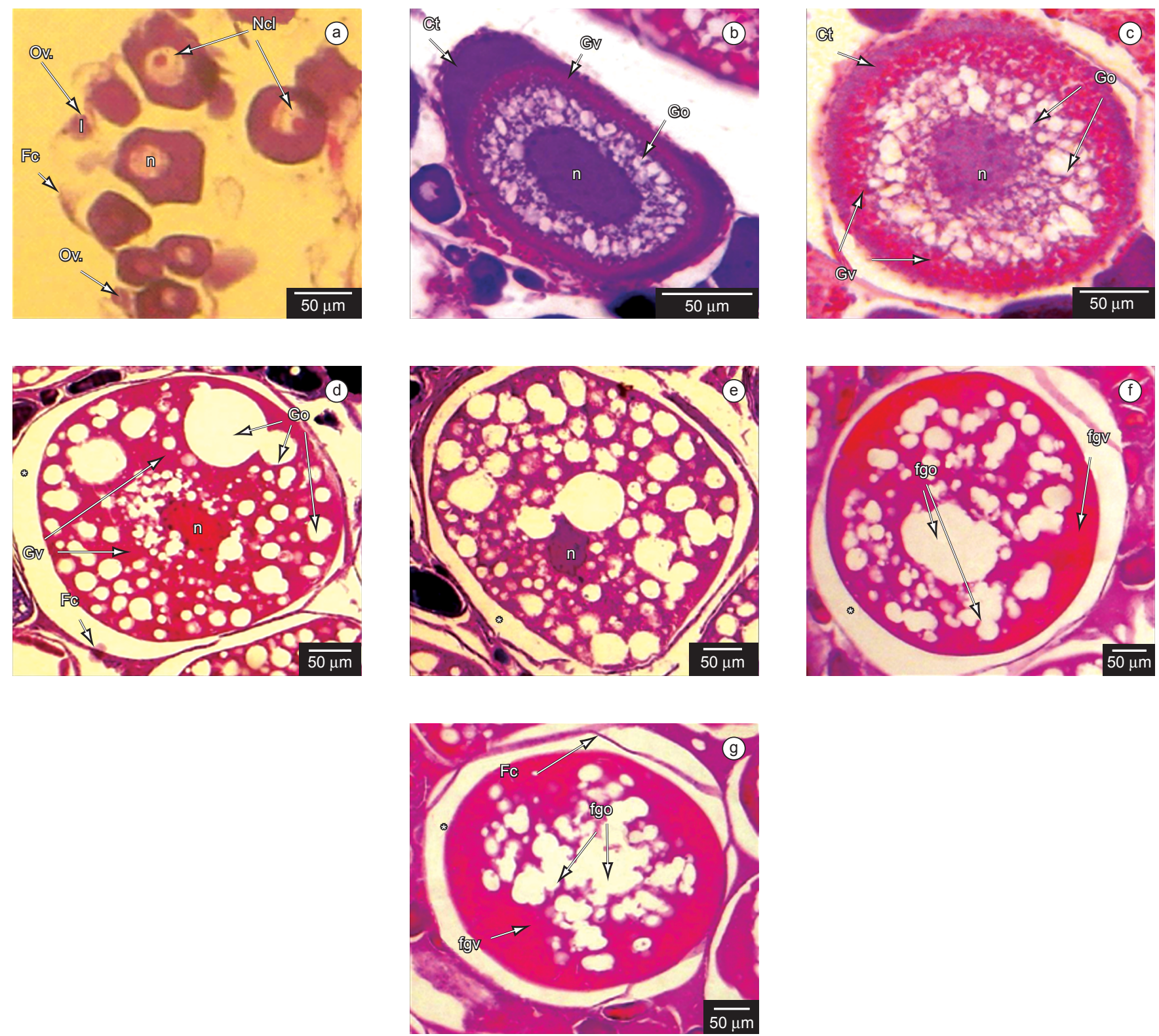

Figura 2. Fases de desenvolvimento das células germinativas: ovogônia e perinuclear (a); vitelogênica e lipídica inicial (b), intermediária (c) e avançada (d), migração do núcleo (e) e pré-ovulação (f e g). Ov: ovogônias; Ncl: nucléolos; Fc: folículo celular; Ct: citoplasma; Go: gotículas de óleo; Gv: glóbulos de vitelo; n: núcleo; fgo: fusão de gotículas de óleo; fgv: fusão de glóbulos de vitelo; *: espaço devido à hidratação pré-ovulatória.

Figure 2. Developmental phases of germinative cells: oogonia and perinucleolar (a); vitellogenic and early (b); intermediate (c) and advanced (d) lipidic; nucleus migration (e) and pre-ovulation (f and g). Ov: oogones; Ncl: nucleoles; Fc: cellular follicle; Ct: cytoplasm; Go: oil droplets; Gv:yolk globules; n: nucleus; fgo: oil droplets' fusion; fgv: yolk globules' fusion; *: space owing to pre-ovulatory hydration.

\subsection{Estádio III (maduro)}

Todos os tipos de células estão presentes no ovário: oócitos nas fases I (40\%), II (12\%), III (4\%) e cerca de 44\% de células entre as fases IV a VI (Figura 4d).

\subsection{Estádio IV (Repouso)}

A disposição das células permite a visualização de um espaço no interior do ovário (Figura 4e), apresentando ovogônias (17\%) e oócitos I em maior quantidade (82\%) e alguns fragmentos celulares em processo de reabsorção.

\section{Discussão}

O presente trabalho fornece as primeiras informações sobre a organização e desenvolvimento ovariano da pescada-do-piauí, Plagioscion squamosissimus, capturada no reservatório de Pedra, localizado no sudoeste da Bahia.

Sob o ponto vista macroscópico, o desenvolvimento ovariano da pescada-do-piauí utilizado no presente trabalho pode ser classificado em cinco estádios maturacionais: imaturo, maturação inicial, maturação avançada, maduro e repouso. Essa classificação é semelhante àquela descrita por Santos et al. (2003), para a pescada-do-piauí capturada em açudes do Ceará. Sabe-se que a terminologia usada 

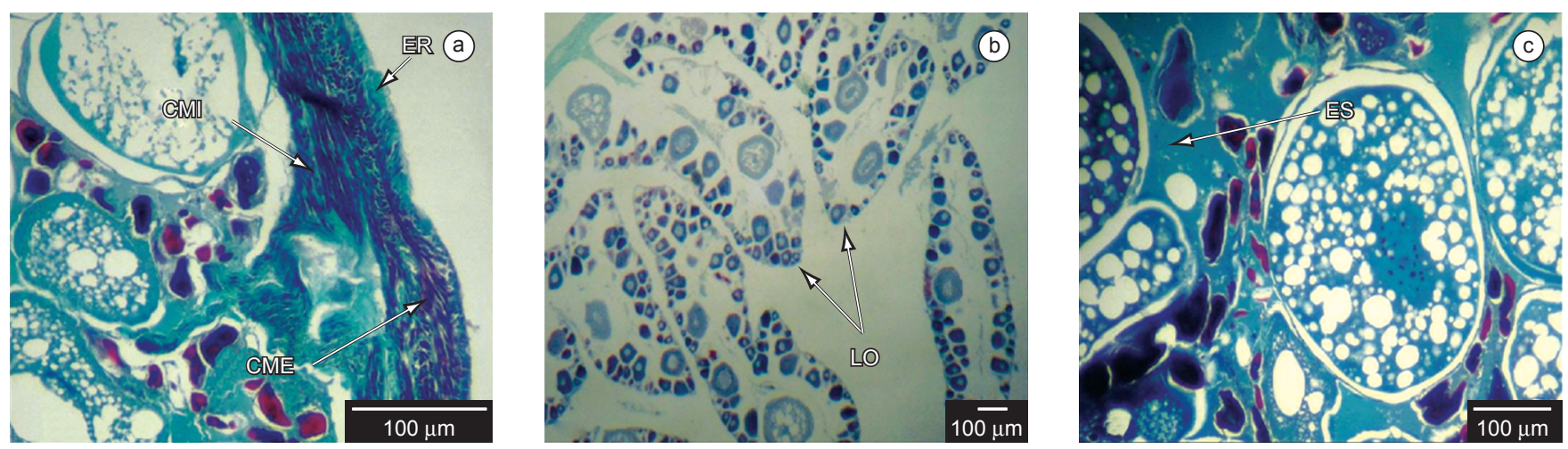

Figura 3. Estruturas celulares de ovários de Plagioscion squamosissimus - Coloração: Tricrômico de Gomori: a) Camada muscular externa (CME), Camada muscular interna (CMI), Epitélio de revestimento (ER); b) Lamelas ovígeras (LO); c) Estroma (ES).

Figure 3. Cell structures of Plagioscion squamosissimus ovaries - Stain: Gomori trichromic: a) External muscular layer (CME), Internal muscular layer (CMI), Surface epithelium (ER); b) Oocyte lamellae (LO); c) Stroma (ES).
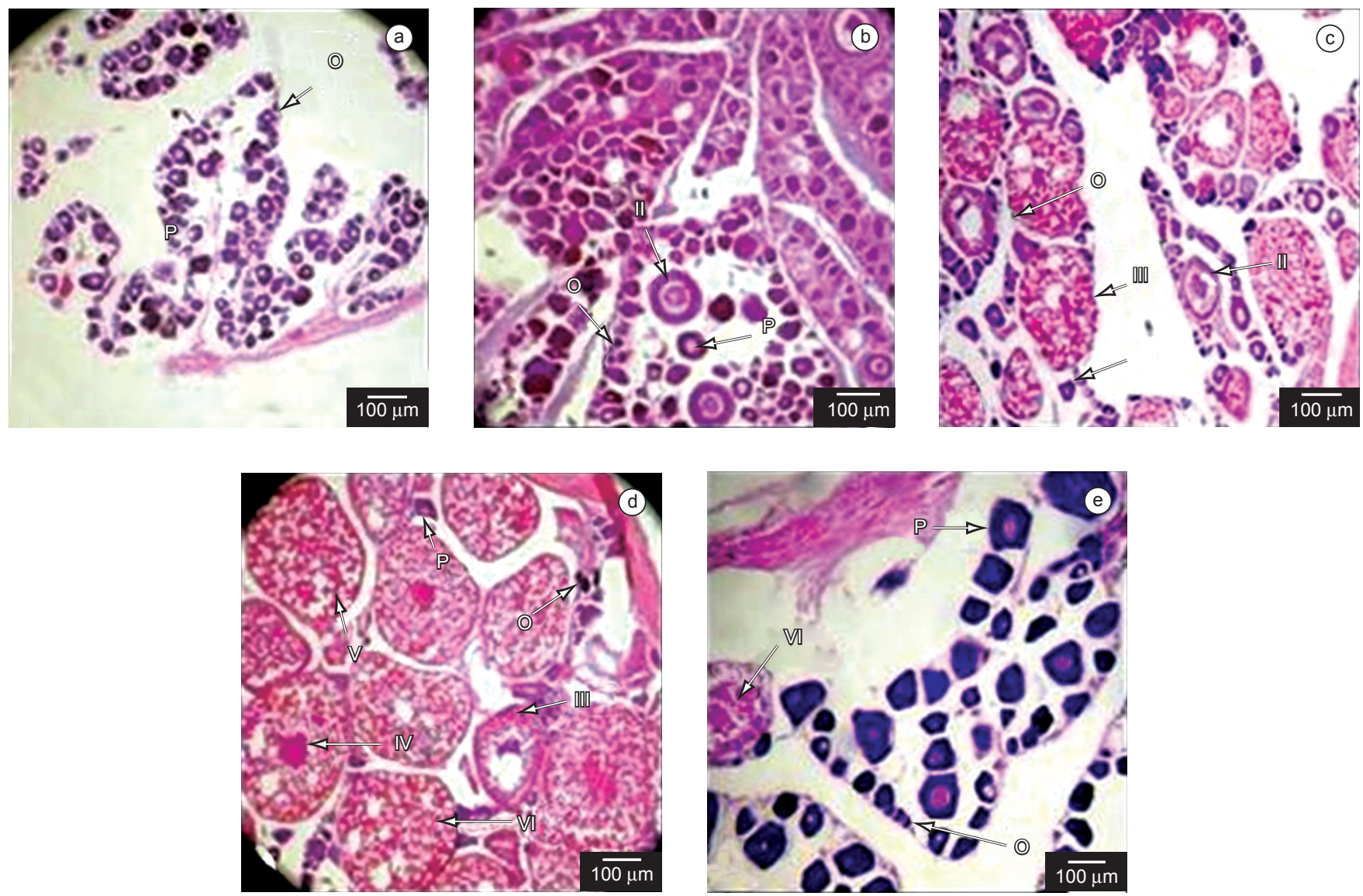

Figura 4. Fotos dos estágios maturacionais dos ovários de Plagioscion squamosissimus. a) Imaturo; b) Maturação inicial; c) Maturação avançada; d) Maduro; e) Repouso. Ovogônia (O); Perinucleolar (P); Vitelogênica e Lipídica iniciais (II); Vitelogênica e Lipídica intermediária (III); Vitelogênica e Lipídica avançada (IV); Migração do núcleo (V); Pré-ovulação (VI).

Figure 4. Maturational stages of Plagioscion squamosissimus ovaries. a) immature; b) initial maturation; c) advanced maturation; d) mature; e) resting. Ooogonia (O); Perinucleolar (P); Vitellogenic and early lipidic (II); Vitellogenic and intermediate lipidic (III); Vitellogenic and advanced lipidic (IV); Nucleus migration (V); Pre-ovulation (VI). 
para a classificação macroscópica de gônadas de peixes teleósteos varia entre autores, em consequiência da espécie estudada e da metodologia aplicada na investigação. De um modo geral, Vazzoler (1996) classifica o desenvolvimento ovariano de peixes teleósteos em cinco estádios maturacionais: imaturo (virgem), em maturação, maduro, esvaziado (em recuperação) e repouso. No presente trabalho, o estádio 'esvaziado' (spent) não foi incluído na classificação, por não terem sido encontradas amostras que o identificassem, ou seja, gônadas com vários oócitos em fase de absorção, formando grumos esbranquiçados e/ou a presença de zonas hemorrágicas.

Microscopicamente, o desenvolvimento ovocitário da pescada pode ser classificado em seis fases: ovogônia e oócito perinucleolar, fase vitelogênica e lipídica inicial, intermediária e avançada, migração do núcleo e a fase pré-ovulatória. Assim como em muitos teleósteos, as ovogônias são as primeiras estruturas a aparecerem dentro do ovário, que é logo seguida dos oócitos perinucleolares. Logo após a fase perinucleolar dos oócitos acontece a vitelogênese endógena, ou seja, o aparecimento das vesículas de vitelo (ou alvéolos corticais), constituídas de glicoproteínas ou polissacarídeos. No presente estudo, porém, essas estruturas não foram claramente identificadas. Sabe-se que a quantidade de vesículas de vitelo depositadas, suas propriedades e o tempo de aparecimento no citoplasma diferenciam de acordo com a espécie (Hibiya 1982, Zanuy \& Carrillo 1987).

É importante ressaltar que a deposição dos glóbulos de vitelo dáse inicialmente na parte mediana do citoplasma, sendo logo seguida da deposição lipídica. As gotículas de óleo surgem na região perinuclear e migram para a periferia do citoplasma nos estágios mais avançados (Nagahama 1983). À medida que o ovário se desenvolve, os glóbulos de vitelo e as gotículas de óleo vão preenchendo todo o citoplasma, havendo em algumas células uma fusão tanto dos glóbulos de vitelo quanto das gotículas de óleo na fase pré-ovulatória.

Além disso, foi observado nessa fase um processo de hidratação pré-ovulatória, caracterizado pelo aumento do espaçamento entre o citoplasma e a membrana do oócito (Matsumoto \& Miyabe 2001, Corriero et al. 2003). Apesar de ser uma espécie com ocorrência restrita à água doce, a pescada-do-piauí pertence à família Sciaenidae, constituída por espécies predominantemente marinhas e estuarinas, ocorrendo apenas quatro gêneros restritos à água doce na América do Sul (Casatti 2003). Sabe-se, também, que a hidratação durante a fase final do desenvolvimento ovariano pode contribuir com quase $90 \%$ do tamanho final do óvulo, que por sua vez é de grande importância na produção de ovos flutuantes, (Tyler \& Sumper 1996), assim como acontece na pescada-do-piauí.

Chaves (1989) considera que espécies primariamente dulciaqüícolas não realizam hidratação pré-ovulatória. Por outro lado, aquelas secundariamente dulciaquícolas, ou seja, de origem marinha, teriam perdido estas características em algum estágio de sua adaptação à água doce, podendo sua ocorrência, entretanto, ser atribuída a uma adaptação incompleta de tais espécies ao ambiente dulciaqüícola.

\section{Agradecimentos}

À Companhia Hidro Elétrica do São Francisco (CHESF) e à Fundação Apolônio Salles de Desenvolvimento Educacional (FADURPE), responsáveis pelo Projeto "Inventário da ictiofauna dos reservatórios de Pedra e Funil", através do qual foram coletados os dados do presente estudo. À FADURPE, pela concessão de bolsa de mestrado a RTSF.

\section{Referências Bibliográficas}

AGOSTINHO, A.A., GOMES, L.C. \& PELICICE, F.M. 2007. Ecologia e manejo de recursos pesqueiros em reservatórios do Brasil. EdUEM, Maringá, 501 p.

BEÇAK, W. \& PAULETE, J. 1976. Técnicas de citologia e histologia. Livros Técnicos e Científicos, Rio de Janeiro, 305 p. (v. 1 e 2).

BEHMER, A., CASTRO de TOLOSA, E.M. \& NETO, A.G.F. 1976. Manual de técnicas para histologia normal e patológica. Faculdade de Medicina da Universidade de São Paulo, São Paulo, 255 p.

CASATTI, L. 2003. Family Sciaenidae (Drums or croakers). In REIS, R.E., KULLANDER, S.O. \& FERRARIS Jr., C.J. Check list of the freshwater fishes of South and Central America. EDIPUCRS, Porto Alegre, p. 599-602.

CASATTI, L. 2005. Revision of the South American freshwater genus Plagioscion (Teleostei, Perciformes, Sciaenidae). Zootaxa. 1080:39-64.

CHAVES, P.T.C. 1989. Hidratação pré-ovulatória em peixes: um caráter de origem marinha? Revta. Bras. Zool. 6(3):463-472.

CORRIERO, A., DESANTIS, S., DEFLORIO, M., ACONE, F., BRIDGES, C.R., SERNA, J.M. de la, MEGALOFONOU, P. \& METRIO, G. 2003. Histological investigation on the ovarian cycle of the eastern Atlantic bluefin tuna (Thunnus thynnus L.). J. Fish. Biol. 63(1):108-119.

Fundação Apolônio Salles de Desenvolvimento Educacional - FADURPE. 2006. Programa de conservação da ictiofauna nos reservatórios das usinas hidrelétricas de Pedra e Funil: $2^{\circ}$ relatório anual e final. FADURPE, Recife, $121 \mathrm{p}$.

HIBIYA, T. 1982. An atlas of fish histology. Normal and pathological features. Gustav Fischer Verlag, Stuttgart, 147 p.

JUNQUEIRA, L.C.U. \& JUNQUEIRA, L.M.M.S. 1983. Técnicas básicas de citologia e histologia. Livraria e Editora Santos, São Paulo, 123 p.

MATSUMOTO, T. \& MIYABE, N. 2001. Preliminary report on the maturity and spawning of bigeye tuna Thunnus obesus in the Central Atlantic Ocean. Col. Vol. Sci. Pap. ICCAT. 54(1):246-260.

NAGAHAMA, Y. 1983. The funcional morphology of teleost gonads. In Fish Physiology (W.S. Hoar, D.J. Randal \& E.M. Donaldson, eds.). Academic Press, London, p. 223-264. (v. 9, parte A).

NASCIMENTO, L.S. 2004. Estrutura da população da corvina de água doce Plagioscion squamosissimus (Perciformes, Sciaenidae) no Reservatório de Pedra - BA. Monografia, Universidade Estadual do Sudoeste da Bahia, Jequié, $84 \mathrm{p}$.

SANTOS, S.B.A.F., SILVA, A.C. \& VIANA, M.S.R. 2003. Aspectos reprodutivos da pescada-do-piauí, Plagioscion squamosissimus (Heckel, 1840), capturada no açude Pereira de Miranda (Pentecoste-Ceará). Rev. Ciência Agronômica. 34(1):5-10.

TYLER, C.R. \& SUMPER, J.P. 1996. Oocyte growth and development in teleosts. Rev. Fish Biol. Fisheries. 6(3):287-318.

TRINDADE, M.E.J. 2006. Dieta e condição da corvina de água doce Plagioscion squamosissimus (Heckel, 1840) (Teleostei, Perciformes, Sciaenidae), num trecho do rio de Contas, sob influência do reservatório da barragem de Pedra. Monografia, Universidade Estadual do Sudoeste da Bahia, Jequié, $37 \mathrm{p}$.

VAZZOLER, A.E.A.M. 1996. Biologia da reprodução de peixes teleósteos: teoria e prática. EdUEM/SBI, Maringá e São Paulo, 169 p.

WELCOMME, R.L. 1988. International introductions of inland aquatic species. FAO Fish. Tech. Pap. (294): 318.

ZANUY, S. \& CARRILLO, M. 1987. La reproducción de los teleósteos y su aplicación en acuicultura. In: Reproducción en acuicultura. CAICYT, Madri, $321 \mathrm{p}$.

Recebido em 21/12/08

Versão reformulada recebida em 02/06/09

Publicado em 30/07/09 